\title{
Laying the foundations for physical literacy in Wales: The contribution of the Foundation Phase to the development of Physical literacy
}

\author{
Nalda Wainwright, Jackie Goodway, Margaret Whitehead, Andrew Williams, David \\ Kirk
}

\begin{abstract}
Background: The Foundation Phase in Wales is a play-based curriculum for pupils aged three to seven years old. Children learn through more holistic areas of learning in place of traditional subjects. As such the subject of Physical Education in its traditional form no longer exists for pupils under the age of seven in Wales. In light of the role of Physical Education in developing physical literacy and in particular the importance of this age group for laying the foundations of movement for life long engagement in physical activity the disappearance of Physical Education from the curriculum could be deemed to be a concern.

Purpose: The purpose of this study was to explore the Foundation Phase as a naturalistic intervention and examine its contribution to the development of physical literacy.

Participants and setting: Participants included year one pupils $(N=49)$ aged five and six from two schools in contrasting locations. A smaller group within each class was selected through purposive sampling for the repeated measures assessments $(N=18)$.

Research design and methods: A complementarity mixed-method design combined quantitative and qualitative methods to study the Foundation Phase as a naturalistic intervention.

Quantitative data were generated with the Test of Gross Motor Development-2 administered to the sample group of children from both schools as a quasi-repeated measure, the physical competence subscale of the Pictorial Scale of Perceived Competence and Social Acceptance and the Leuven Involvement Scale for Young Children. Qualitative data were generated throughout the study from analysis of video and field notes through participant observation. Data from the mixed methods were analysed through complementarity to give a rich insight into pupils’ progress and experiences in relation to physical literacy.

Results: Overall analysis of the data from TGMD-2 showed significant improvements in the Gross Motor Quotient and Locomotor skills from T1 to T3, but no significant improvement in object control. Data from qualitative methods were analysed to explore processes that may account for these findings. Video and field notes complement the quantitative data highlighting that children were developing their locomotor skills in many aspects of their learning. Observations using the Leuven Involvement Scale indicated that children had high levels of involvement in their learning and apparent in video and field notes was pupils' motivation for movement. Paired sample t-tests $(N=18)$ conducted on the Harter and Pike perceived physical competence six item score subscales (T1 and T3) indicated a significant difference in the mean perceived physical competence scores on the six-item scale between T1and T3. Qualitative data explored pupils' confidence for movement in many areas of learning.

Conclusion: The combination of quantitative and qualitative data indicates that the Foundation Phase is an early childhood curriculum that lays the foundations of physical literacy with the exception of object control skills, which are strongly associated with later engagement in physical activity. The development of specific physical skills such as object control skills may need more specialist input with early childhood pedagogy teachers trained in motor development to see significant improvements.
\end{abstract}

Key Words: Physical Education, physical literacy, motor development, early childhood, play, 
pedagogy.

\section{Introduction}

The Foundation Phase in Wales is a child centred curriculum for pupils aged 3 -7 years that advocates learning through 'first hand experiential activities with the serious business of play providing the vehicle' (DCELLS, 2008:4). The introduction of this play-based curriculum in 2008 follows a worldwide trend within education systems which sees subject matter clustered into more holistic areas of learning that extend beyond traditional subjects; as such, physical education as a subject no longer exists in Wales for pupils under the age of seven (Macdonald, 2003; Maynard, 2007; Author 2016; DCELLS, 2008).

Research in the field of motor development highlights the importance of early childhood in the laying of foundations for life long physical activity (Barnett et el., 2009; Barnett et al., 2016; Clark and Metcalf, 2002; Stodden et al., 2008;) and in light of the importance of physical education for the development of physical literacy (Hardman, 2011; Talbot, 2007; Whitehead, 2010) the loss of physical education as a subject for all pupils in Wales under the age of seven could be viewed as a cause for concern. However, the play-based nature of the curriculum means that physicality is central to all learning and many of the attributes of physical literacy may well be developed through this holistic approach to learning.

This paper explores the discourse around physical education and physical literature, highlighting implications for the Foundation Phase in relation to physical literacy before reporting aspects of an in-depth study of the implementation of the Foundation Phase and its contribution to pupils' physical literacy. Findings are reported in relation to the attributes of physical literacy of 'motivation, confidence and physical competence and effective interaction with the environment' which 'are the three attributes that form the kernel of the concept and are mutually reinforcing’ (Whitehead, 2010:14).

\section{Physical education and physical literacy}

The nature and purpose of physical education has and continues to be the focus of much debate (Brown, 2013; Hastie, 2017; Kirk, 2010). A growing body of literature calls for learning in Physical Education to be authentic, relevant to learners and holistic in nature (Brown, 2013; Haerens et al., 2011; Kirk, 2010; Stolz, 2013). Contributing to this debate is the concept of physical literacy (Dudley, 2015; Jurbula, 2015; Whitehead, 2001, 2010, 2013), which Whitehead defines as 'the motivation, confidence, physical competence, knowledge and understanding to value and take responsibility for engagement in physical activities for life' (Whitehead, 2016). Physical literacy is recognised in literature, research and policy as an outcome of Physical Education (Hardman, 2011; Talbot, 2007). Whitehead expresses the philosophical belief from existentialism and phenomenology that embodiment is central to 
Although Brown and Payne (2009:419) suggest 'the contribution of phenomenology to the physical education discourse is and remains on the margins', there is a growing discourse in the fields of physical education and philosophy concerned with embodiment in physical education, sport and the construction of the self (Birch, 2009; Block and Weatherford, 2013; Brown and Payne, 2009; Brown, 2013; Hopsicker, 2009; Stolz, 2013). Stolz (2013:950) in particular is critical of the academisation of physical education, suggesting that this has led to a disconnect in physical education from its purpose 'to develop each person's whole being' and both Stolz (2013) and Whitehead (2010) draw on the work of Merleau-Ponty who argues humans do not view the world from outside, but are themselves part of it and as such are 'beings-in-the-world' (Merleau-Ponty, 1962:58). As such humans 'create themselves as they interact with their surroundings' and are 'forever in an active relationship with the world known as intentionality' (Whitehead, 2010:26). Whitehead (2010:26) further explains that 'the intentionality in which our embodiment plays the leading role is known as operative intentionality.' This is of particular significance in relation to the nature of the Foundation Phase as a play-based curriculum, where children's operative intentionality is the means for them to learn about the world and their place as part of it. Indeed, young children at play is perhaps one of the most obvious examples of the innate drive to interact with the world where the relationship between perception and movement function inseparably as children construct their understanding of themselves (Merleau-Ponty, 1962).

\section{The Foundation Phase}

The Foundation Phase is a play-based, holistic, child-centered approach to education for children aged three to seven, underpinned by childhood well-being (DCELLS, 2008). Influenced by a range of international approaches such as Reggio Emilia in Northern Italy, Te Whāriki in New Zealand and Forest Schools in Scandinavia an appropriate learning environment is central to Foundation Phase provision. Curriculum documentation advocates the use of indoor and outdoor spaces which are exciting, fun, stimulating and safe, and which promote discovery and independence (DCELLS, 2008). The 'use of the outdoors for learning' is one of four key features of the Foundation Phase, along with 'play and active learning' 'child-initiated learning' and 'focused adult led sessions' (Author, 2016). These key features are evident across all learning which often sees literacy and numeracy activities taking place outside in the form of treasure hunts or other such activities in stark contrast to traditional learning at desks.

The outdoor environment as a valued resource for children's learning is well recognised (Maynard and Waters, 2007; Waite, 2010) with research focused on learning in the natural environment demonstrating increased levels of physical activity (Mygind, 2007) and improved motor development (Fjørtoft, 2004). Maude (2010) suggests there is overwhelming evidence for the benefits of both indoor and outdoor play for providing opportunities for children to develop awareness and understanding of their embodied dimension. As Broadhead (2004:89) 
who and what they are and know' and it is how they explore who and what they may become. This understanding of play aligns with a monist philosophical perspective of 'viewing the person as essentially an indivisible whole', which is 'fundamental to the appreciation of the concept of physical literacy’ (Whitehead, 2010:22).

\section{Playful pedagogy}

The Welsh Government recognises the importance of play as a way 'children become selfaware' and 'learn social rules' as well as being 'fundamental to intellectual development' (DCELLS, 2008:6). However, Wood and Attfield (2005:5) emphasise that defining play is problematic as it 'is always context dependent' and can be in many different forms. As a playbased curriculum the interpretation of play in the Foundation Phase is not clearly defined. Howard and McInnes (2010:34) suggest that 'viewing playfulness, as an attitude of mind, rather than play, the outward act, may be the most helpful way of thinking about this elusive concept and of providing a theoretical basis for implementing a play-based curriculum' such as the Foundation Phase. They further propose that utilising a concept of play which is based on children's perceptions, highlighting playfulness as an approach and attitude to an activity may help to develop practitioners' understanding of play. Howard and McInnes (2010:35) highlight how children make the distinction between work and play with clear cues illustrated in table 1 .

\section{Table 1}

McInnes et al. (2009:122) propose that it is not whether the activity is play or not that is the issue, but rather 'the playful approach and attitude that is taken to an activity'. Although the experiences in the Foundation Phase are in the main conceived, designed and introduced by teachers, it is the choices about how they engage with tasks that makes the learning experiences playful. Maude (2010:111) highlights the important relationship between play and physical literacy, as she explains that play 'facilitates the establishment of many of the other attributes that are characteristic of a physically literate individual, including motivation, confidence, environmental and interpersonal engagement, self-knowledge and self-expression.' The notion of playful pedagogy where children learn in a way that they perceive as play is seen in the Foundation Phase across all areas of learning, thus maintaining motivation and engagement in the task (Author, 2016; Howard and McInnes, 2010).

The links between play and high levels of involvement and intrinsic motivation have been well documented (Brock et al., 2009; Howard and McInnes, 2010, 2011; Moyles, 2010). By using a playful pedagogy teachers create an autonomy supportive climate (Hastie et al., 2013). Deci et al. (1991) emphasise the significance of an autonomy supportive climate in determining the level of self-determination and intrinsic motivation. Motivation is strongly related to engagement and this concept is important to this study as Reeve et al., (2004) highlight it is considered to represent a behavioural pathway of motivational processes that contribute to students' subsequent learning and development and as such predicts underlying motivation, an attribute of physical literacy. 


\section{Physical development}

Although physical literacy is far broader than the attribute of physical competence, literature from the field of motor development and health highlight the importance of early childhood for laying the foundations of physical development and the physical competence needed for later engagement in more structured physical activity and sport (Barnett et al., 2009; Barnett et al., 2016; Clark and Metcalf, 2002; Stodden et al., 2008). Although there is some evidence that play in a natural environment will develop physical competence, it is a misconception that

through just playing, physical competence will simply occur naturally (Barnett et al., 2016; Gallahue, Ozmun, and Goodway 2012; Haywood and Getchell 2009; Hürmeriç, Altunsöz and Goodway, 2016). For children to realise the full potential of their movement vocabulary, they need developmentally appropriate structured opportunities with informed feedback (Maude, 2010; Hürmeriç Altunsöz and Goodway, 2016; Goodway and Branta 2003). Although the Foundation Phase is a play-based curriculum featuring 'child-initiated learning' the curriculum does still retain 'focused adult led sessions' which despite the lack of Physical Education as a subject does give opportunities for the structured teaching for the development of physical competence (Author, 2016).

From this literature it could be argued that despite the loss of physical education in its traditional form, the play-based active nature of the Foundation Phase may still make a positive contribution to the development of attributes of physical literacy. The following section reports on data drawn from a large study of the contribution of the Foundation Phase to the development of physical literacy.

\section{Research Design}

To gain a deep understanding of the complexities of the Foundation Phase curriculum and its contribution to the holistic concept of physical literacy a mixed methods pragmatist approach was required. The study combined quantitative and qualitative paradigms in a complementarity mixed-method design enabling measurement of overlapping but also different facets of learning to yield an enriched and elaborated understanding of the Foundation Phase as a naturalistic intervention (Greene et al., 1989). Drawing on the view that 'epistemological purity does not exist' this study aligned to the view of Onwuegbuzie and Leech (2005:377) who argue for the terms 'confirmatory and exploratory' in place of quantitative and qualitative therefore seeking to confirm whether outcomes in relation to physical literacy were being achieved and explore how. In so doing it was not concerned with whether the Foundation Phase was the 'cause' of pupil progress but rather explored pupils' experience of the Foundation Phase. This paper reports the findings from phase two of a three phase complementarity mixed methods study. Phase one generated inductive data from documentary analysis and interviews to identify expected outcomes of the Foundation Phase related to physical literacy. Findings from phase one informed the selection of methods for phase two. Phase two assessed whether and how the physical literacy outcomes were being achieved. Phase three explored the relationship between physical literacy and academic achievement. Table two shows the research design for the 
measures, methods were used as and when possible to cause least disruption to the routines of the schools.

\section{Table 2}

\section{Participants}

The study aimed to ascertain the experience of pupils in the Foundation Phase therefore it was important that practice in the schools was a true representation of that curriculum. As such schools two schools were selected for the study on the basis of recognition of high quality Foundation Phase provision by government inspectors and advisors. The schools were in contrasting locations although this was not a condition for selection. School A was a small rural

school with a mixed socioeconomic catchment area. School B was a large urban school with children mainly from low socioeconomic backgrounds.

Data reported in this paper were from a year one class in each school. The year one class in school A had twenty-three pupils (thirteen girls and ten boys) in total, school B had twenty-six pupils (fourteen girls and twelve boys) in total $(N=49)$ aged five and six. All pupils in the two classes were involved in the study and a further smaller group within each class was selected through purposive sampling for repeated measures assessments. The smaller sample group was selected through discussion with the teachers and support staff to obtain a mixed ability sample based on the teachers' judgment of the children's physical competence. A total of eight pupils from each school were selected for the repeated measures assessments and two extra in case of absence $(N=18)$.

\section{Ethics}

The University code of ethics and BERA Ethical Guidelines for educational research (2004) were adhered to. Voluntary informed consent was sought for all participants, permission from adults responsible for the children and participant assent from the children.

\section{Methods}

In the absence of a physical literacy assessment for Foundation Phase age pupils at the time of the study, a range of methods were selected and piloted. The combination of data from the methods were used to confirm and explore pupils' progress in physical literacy outcomes identified in phase one of the study as; physical competence and interaction with the environment, motivation and confidence.

Physical competence and interaction with the environment was assessed with the Test of Gross Motor Development, second edition (TGMD-2), video and field notes. The TGMD-2 was administered to the sample group of children from both schools $(n=18)$ as a quasi-repeated measure at Time 1 February, Time 2 July and Time 3 December. Administration of the assessment followed the standardised and established guidelines for each participant. Trials of the TGMD-2 were videotaped for coding. TGMD-2 is a criterion- and norm-referenced 

children between the ages of three and ten years, consisting of two sub-tests measuring object control and locomotor skills (Ulrich, 2000). Raw subset scores were converted to standardised scores and combined to give the Gross Motor Quotient (GMQ) which Ulrich (2000:3) states 'is the best measure of an individual's overall gross motor ability.' The TGMD-2 provides a valid and reliable measure of fundamental motor skill performance and is a widely used instrument in motor development literature (Goodway and Branta, 2003; Valentini and Rudisill, 2004b).

Video and participant observation field notes further explored pupils' physical competence and interaction with the environment. Video to captured the context in particular when many different activities were happening simultaneously. Video observations took place over the year as and when it was possible to fit in with the life of the schools. During phase two twenty-nine videos were filmed in School A and thirty-seven were filmed in School B, giving a total of eighty-nine videos.

Participant observation field notes generated data to glean greater understanding of pupils' experiences of the Foundation Phase. Self-reflection supported the use of field notes recorded both in situ and later to ensure 'a detailed record of both objective observations and subjective feelings,' maintaining a high level of reflexivity (Spradley, 1980:58). Pages and lines in the field note journal were numbered clearly in order to have a clear trail of all comments back to their source throughout the process of analysis. A total of 281 pages of field notes were recorded.

Pupil confidence was assessed with the Pictorial Scale of Perceived Competence and Social Acceptance (PSPCSA) for pre-school and kindergarten age children (Harter and Pike, 1984) in conjunction with video and field notes (as outlined above). In this study only the physical competence subscale of the PSPCSA was used and although previous research suggests children of this age are inaccurate in their judgements of perceived competence (Goodway and Rudisill, 1997) this scale has been used extensively in research with pupils of this age (Valentini and Rudisil, 2004; Robinson et al., 2009; Robinson, 2011). The six-item physical competence subscale was administered to the sample group of children from both schools $(N=18)$ at Time 1 February and Time 3 December. Each item was scored on a four-point scale, where a score of four would be the most competent and a score of one would designate the least competent the mean of the scores was calculated for each child.

Pupil motivation was assessed using the Leuven Involvement Scale for Young Children (LISYC) video and field notes (as outlined above). The LIS-YC is part of the evaluation instrument for identifying engagement and deep level learning (Laevers, 1994). The LIS-YC five-point scale gives a score based on a set of observed behaviour or signals. LIS-YC observations were carried out throughout the study across phase two in both schools as opportunities arose in the normal day to day life of the Foundation Phase. The assessment was administered as per guidelines in the manual and observations were carried out in activities that were 'the normal course of affairs' (Laevers et al., 2005:2). Sixty-one LIS -YC observations in total were carried 
in both schools with thirty-five different pupils.

\section{Validity, trustworthiness and legitimation}

As mixed methods research this study aligns to multiple validities legitimation, where the use of multiple methods in combination required consideration of how validities were addressed and achieved for each method and in particular in the integration of methods to make the 'whole greater than the sum of its parts' (Onwuegbuzie and Johnson, 2006:293). Internal validity applied to all methods which Onwuegbuzie and Leech (2006:234) define as 'truth value, applicability, consistency, neutrality, dependability, and/or credibility of interpretations and conclusions within the underlying setting or group'. However, in this study with such small numbers of participants in particular in the repeated measures tests $(n=18)$ external validity claims of generalization could not be considered valid. In order to address dangers of bias in naturalistic methods, Walker (2012:78) emphasises the need for 'constant attention to selfreflection and self-critique'. This was achieved throughout the study by the constant keeping of reflections in field notes both in the field and retrospectively. Peer debriefing was also used to aid the process of reflection.

\section{Analysis of data}

Several analytical strategies were used throughout the study for the integration of data from multiple methods. Typology development combined data from observations and field notes to give an 'explanatory variable for the statistical analysis' (Carnacelli and Greene, 1993:235). Extreme case analysis identified examples from the analysis of one data type which were 'pursued via analysis of data of the other type' (Carnacelli and Greene, 1993:235). Data consolidation and merging jointly reviewed different data types to create qualitative narratives from observations and video enabling analysis with interviews that allowed for deeper insights from new data (Carnacelli and Greene, 1993:242). Qualitative data were analysed using the constant comparative method of inductive data analysis (Gray, 2014).

\section{Findings and discussion}

Analysis of the qualitative and quantitative data found that the Foundation Phase made a positive contribution to the components of physical literacy of competence and effective interaction with the environment, motivation and confidence, with the exception of object control skills.

\section{Physical competence and interaction with the environment}

Analysis of data from TGMD-2, video and field notes found that Pupils in the Foundation Phase had good levels of physical competence and showed a significant improvement in their locomotor skills. However, object control skills did not improve significantly.

Overall analysis of the data from TGMD-2 showed significant improvements in the Gross Motor Quotient and locomotor skills from Time 1 to Time 3, but no significant improvement in object control. A repeated measures ANOVA was conducted across the three time frames of the studv (Time 1. Time 2. Time 3) with a Bonferroni adiustment of the alpha level built into 
the analyses, in order to adjust for multiple comparisons that took place.

The repeated measures ANOVA was undertaken for the: 1) GMQ, 2) locomotor SS, and 3) object control SS for the overall group. The ANOVA with repeated measures for the GMQ revealed a significant multivariate main effect for Time, $\mathrm{F}(2,16)=15.35, p<.001$, Eta squared .66. A similar finding was found for the ANOVA with repeated measures for locomotor skills, $\mathrm{F}(2,16)=24.17, p<.001$, Eta squared .75 . However, for object control skills there was not a significant main effect, $\mathrm{F}(2,16)=3.17, p=.069$, Eta squared .28 . These findings identify that the significant improvement in the GMQ is related to the significant improvement in locomotor skills whilst object control skills did not show a significant improvement. The research design does not allow for direct attribution as pupils have only had experience of the Foundation Phase and so data from qualitative methods were analysed to explore processes that may account for these findings.

Video and field note observations highlighted that children were developing their locomotor skills in many aspects of their learning and interacting with a variety of environments. For example, a mathematical development session in School A showed how the pupils were developing their locomotor skills whilst engaged in activities as part of a maths trail: 'After lunch is a maths trail-Easter egg maths trail, Mrs. Smith hides the questions outside around the grounds. Sarah and Ann have their clipboard and jog off to the steps to head up onto the grass. Jo and Cai have theirs and Jo points the way with his pencil "up here, up on the grass"

he shouts, Cai has the clipboard under his arm and they run over to the wall and climb up with ease onto the grass. Peter and Dai run past, "where did you see it?" shouts Dai, "up here" says Peter, Dai heads up on the steps and they run across to the football posts near Jo and Cai' (Field notes school A p72, line 15 - FNA72,15). 'The children run between cards and find the questions, climbing over and running around the parts of the trim trail' (Video 7 school A clip a - V7Aa). 'They play climbing and swinging for a while then the majority of the class head to 'the mound' and play a running and chasing game up and down' (V7Ae).

Although the lesson had been planned as an activity for mathematical development, the children were using locomotor skills throughout. Not only did the activity of a trail (in essence an early form of orienteering) encourage the pupils to run, but the use of the natural terrain and the obstacles of the trim trail meant that children were running, climbing, leaping and jumping, demonstrating the type of activities that Fjørtoft (2004) highlights as vehicles for motor development.

Field notes also identified occasions when pupils demonstrated object control skills such as during a free choice activity session 'Llion plays football, Megan plays with a hoop and target game. Iestyn is playing with a bat and ball whilst Elin is making a game with skittles a bean bag and ball' (FNB 60, 14). The children played these activities independently with no intervention from the teacher. There were also opportunities to practice throwing skills in areas of the curriculum such as mathematical development where the, 'children throw the bean bags 
(FNA 101, 2). Planned whole class physical development sessions using ball skills were also observed. However, teacher intervention was limited and did not include structured feedback in relation to developmental stages of skills, 'Sara's throwing is erratic, she throws over-arm too hard - Sue (the teacher) says she may be better underarm - she is much better' (FNA 101, 17).

Literature highlights that the development of physical skills requires teacher input and does not just happen naturally (Goodway and Branta, 2003; Goodway, Suminski, and Ruiz, 2003). Fundamental motor skill development is complex. Teachers and coaches can manipulate different factors or constraints to influence the development of a new skill and 'promote motor development of children' (Gallahue et al., 2013: 187). Limited teacher intervention as highlighted in field notes may have impacted on pupils' development of object control skills. The relationship between physical competence and physical activity is well documented (Barnett et al., 2016; Clark and Metcalf, 2002; Stodden et al., 2008) and children proficient in object control skills are more likely to be physically active adolescents (Barnett et al., 2009). Therefore, these findings raise questions about the Foundation Phase and implications for lifelong physical activity.

\section{Motivation}

Analysis of data from Leuven Involvement Scale, video and field notes found that pupils were highly engaged in their learning and motivated to move in a variety of contexts. Leuven Involvement Scale observations assessed the levels of the pupils' involvement in their activities and as such contributed to the assessment of their motivation and engagement. The Leuven scale is scored from one to five with one being extremely low where the child's activity is simple, repetitive and passive and five being extremely high where the child shows continuous and intense activity revealing the greatest involvement (Laevers, 2000). Table 3 shows the

scores for observations using the Leuven Involvement Scale.

Table 3.

The mean score of 3.7 indicates that children had high levels of involvement in their learning as can be seen in Table 6. 58.09\% of all observations were scored in the high / very high category and only $16.1 \%$ were in the very low/ low category. These findings were high in relation to previous research where post-test scores after an intervention to improve involvement were 3.47 (Laevers and Declercq, 2011).

Table 4:

Observations were categorised in relation to teacher directed and child choice as shown in table 5. A Chi-squared analysis was undertaken to examine if engagement levels were different in teacher selected task or child selected task. The categories of very low and low were combined and high and very high were combined in order to have large enough numbers of the Chisquared analysis, although two cells were still below 5 . The Chi-squared analysis found higher levels of engagement in tasks that the child selected with significance of $p=.021$. The data indicates higher levels of involvement for pupil directed tasks. This supports previous studies 
where autonomy support - defined as valuing ‘self-initiation’, ‘children's choice, independent problem solving, and participation in decision making' - is strongly associated with intrinsic motivation (Deci and Ryan,2000; Deci et al., 1994:123).

Table 5:

Field note data complement these findings with observations commenting on pupil engagement across a range of activities. High levels of engagement were particularly evident in child choice activities as it was 'quite remarkable to see how busy, focused and engaged the children were during the free choice time' (FNB 92, 11). The consistent theme with this curriculum was high levels of engagement by the majority of pupils most of the time. Even in teacher-led activities when children were less engaged, the levels of engagement were still high with $76.9 \%$ of observations for the teacher-directed tasks still in the moderate to very high categories. This may have been related to the playful nature of the tasks, as activities included cues that children associate with play (Howard and McInnes, 2010). In particular tasks were often outside, fun and involved moving around.

The motivation for movement can be both extrinsic and intrinsic, but of particular importance to the development of pupils' physical literacy is 'embodiment-as-lived' and physical experiences for their own intrinsic worth (Brown, 2013; Whitehead, 2010:2). This was evident throughout the children's learning. Video in School A showed, 'Stuart, observing the children making boats for the stones to float in was very excited... He jumps up and down on the spot and skips excitedly saying "wow that would be impossible". His actions are a visible expression of his excitement and he skips off to another activity' (V1, A). In free play 'Lily is doing yoga stance in the playground and Ann is on the grass alongside the trim trail, she is cartwheeling over and over again. Some of the other children are on the trim trail spinning around the rope or hanging from the bars. Children run in and out of the willows and they seem to be enjoying the freedom of just running as there does not appear to be any game that they are playing' (FNA $67,21)$.

Analysis of complementary data suggest that children consistently demonstrated movement responses in their daily activities. The nature of the curricula environment in which they were learning appeared to afford opportunities for children to respond in this way. Thus, the Foundation Phase curriculum and children's responses to it 'resonate with embodied competences’ with children knowing 'intuitively how to move’ (Whitehead, 2010:51).

\section{Confidence}

Analysis of data from the Pictorial Scale of Perceived Physical Competence video and field notes found that pupils' perception of their own physical competence improved significantly between Time 1 and Time 3 and they were confident to move in a variety of contexts during many aspects of their learning. Paired sample t-tests $(N=18)$ were conducted on the Harter and Pike perceived physical competence six item score subscales across the Foundation Phase (Time 1 and Time 3). The mean score at Time 1 was 3.14 equating to a child who thought they were 'pretty good' in the area of physical competence. The mean score at Time 3 was 3.34 also equating to the 'pretty good' category in physical competence. There was a significant difference in the mean perceived physical competence scores on the six 
Interestingly pupils viewed themselves as "pretty good" and their scores on the six-item scale improved significantly between Time 1 and Time 3. Previous research indicates that interventions to develop physical competence, when delivered in a mastery motivational climate, have a significant impact on perceived physical competence (Logan et al., 2013; Robinson, 2011; Valentini and Rudisil, 2004). Although in this study there was no intervention, the Foundation Phase is a highly active play-based curriculum where pupils have high levels of physical activity. The autonomy supportive approach of the Foundation Phase along with these high levels of physical activity may have resulted in them perceiving themselves to be highly physical beings and as such see themselves as physically competent. These high levels of perceived competence are important in relation to engagement in physical activity and as such to the development of physical literacy.

Field notes show that children were highly engaged in physical activity across many areas of learning and across phase two of the study from Time 1 to Time 3. During a maths session outside 'Elin runs around saying she is doing shapes using the language "curved" '(FNB 52,11). Pupils were active in their learning and happy to engage in physical activity, 'Sean and Llion climb into and out of the boat. Carter and Nicole play a chasing game' (FNB 205, 21). 'Tom and Carter run together, Tom says 'amazing' they are in a quiet section and seem to be devising a game. Carter leads and Tom follows. They are playing some sort of pretending game... They progress the same game into a bigger area doing the sound effects as they climb, run, jump and crawl all around' (FNB 169, 20).

Perception of physical competence is related to motivation to engage in physical activity (Stodden et al., 2008). Physical literacy is developed through engagement in physical activity and also contributes to engagement in physical activity. Therefore, children's perceptions about their physical competence are an important factor in the development of physical literacy.

\section{Conclusion}

The Foundation Phase curriculum in Wales gave a unique opportunity to study the impact of a naturalistic intervention. Findings suggest that the holistic play-based Foundation Phase with its active embodied learning and use of the outdoors enabled pupils to interact with a diverse range of environments through many areas of learning contributing to locomotor skills, engagement

in learning and perceived physical competence. Analysis of data from multiple mixed methods data suggested that the Foundation Phase as an early childhood curriculum lays the foundations of physical literacy with the exception of object control skills.

The physical play-based approach to learning afforded opportunities across many areas of learning for experiences that were traditionally delivered in physical education. However, although the Foundation Phase contributes to the development of physical literacy, the development of specific physical skills such as object control skills may need more specialist input raising questions about professional development in motor development for early childhood teachers and practitioners. 


\section{References}

Barnett, L., van Beurden, E., Morgan, J., O Brooks, L. and Beard, J. (2009) Childhood Motor Skill Proficiency as a Predictor of Adolescent Physical Activity. Journal of Adolescent Health 44(3) pp 252-9

Barnett, L., Stodden, D., Cogen, K., Smith, J., Lubans, D., Lenoir, M., Livonen, S., Miller, A., Laukkanen, A., Dudley, D., Lander, N., Brown, H. and Morgan, P. (2016) Fundamental Movement Skills: An Important Focus. Journal of Teaching in Physical Education 35(3) pp. 219-225

Birch J. (2009) ‘A Phenomenal Case for Sport’, Sport, Ethics and Philosophy, 3(1), pp. 30-48.

Block, B. and Weatherford, G. (2013) 'Embodied Identities: Using Kinesiology Programming Methods to Diminish the Hegemony of the Normal', Quest, 65(1), pp. 31-43.

Bresler, L. (2004) Knowing bodies, moving minds: Towards embodied teaching and learning, Netherlands: Kluwer Academic publishers

Broadhead, P. (2004) Early years play and learning: developing social skills and cooperation. London: Routledge.

Brock, A., Dodds, S., Jarvis, P. and Olusoga, Y., (ed.) (2009) Perspectives on Play Learning for Life, Harlow: Pearson.

Brown, T.D. (2013) 'A vision lost? (Re) articulating an Arnoldian conception of education 'in’ movement in physical education', Sport, Education and Society, 18(1), pp. 21-37.

Brown, T. D. and Payne P. G. (2009) 'Conceptualizing the Phenomenology of Movement in Physical Education: Implications for Pedagogical Inquiry and Development’, Quest, 61:4, pp. 418-441

Clark, J.E. and Metcalf, J.S. (2002) 'The mountain of motor development: A metaphor', in Clark, J.E. and Humphrey, J.H. (ed.) Motor Development: Research and Review: vol. 2, Reston, VA: NASPE Publications, pp. 62-95.

Cohen, L., Manion, L. and Morrison, K. (2011) Research methods in education, London: Routledge. ( $7^{\text {th }}$ Edn.) 
Deci, E.L., Eghrari, H., Patrick, B.C. and Leone, D.R. (1994) 'Facilitating internalization: The self-determination theory perspective', Journal of Personality, 62(1), pp. 119-142.

Deci, E.L., Vallerand, R.J., Pelletier, L.G. and Ryan, R.M. (1991) 'Motivation and Education: The Self-Determination Perspective,’ Educational Psychologist, 26(3), pp. 325-346.

Dudley, D., (2015) A conceptual model of Observed Physical Literacy. The Physical Educator Vol 72, pp 236-260.

Fjørtoft, I. (2004) 'Landscape as play-scape: The effects of natural environments on children's play and motor development', Children Youth and Environments, 14(2), pp. 21-44.

Gallahue, D.L., Ozmun, J.C. and Goodway, J.D. (2012) Understanding Motor Development: Infants, Children, Adolescents and Adults ( $7^{\text {th }}$ edition), Boston: McGraw-Hill.

Glaser, B.G. and Strauss, A.L. (1967) The Discovery of Grounded Theory, Chicago, IL: Aldane.

Goodway, J.D. and Branta, C.F. (2003) 'Influence of a motor skill intervention on fundamental motor skill development of disadvantaged preschool children’, Research Quarterly for Exercise and Sport, 74(1), pp. 36-46.

Goodway, J. D. and Rudisill, M.E. (1997) 'Percieved physical competence and actual motor skill competence of African American preschool children’ Adapted Physical Activity Quarterley, 20(3), pp298-314

Gray, D. (2014) Doing research in the real world. London: Sage

Greene, J.C., Caracelli, V.J. and Graham, W.F. (1989) 'Toward a conceptual framework for mixed-method evaluation designs’, Educational Evaluation and Policy Analysis, 11(3), pp. 255-274.

Haerens, L., Kirk, D., Cardon, G. and De Bourdeaudhuij, I. (2011) 'Toward the development of a pedagogical model for health-based physical education’, Quest, 63(3), pp. 321-338.

Hardman, K. (2011) Physical education, movement and physical literacy in the twenty-first

century: pupils' competencies, attitudes and behaviours. Paper presented at the $6^{\text {th }}$ FIEP European Congress, 18-21 June, Porec, Croatia.

Harter, S. and Pike, R. (1984) 'The pictorial scale of perceived competence and social 
Hastie, P. (2017) Revisiting the National Physical Education Content Standards: What Do We

Really Know About Our Achievement of the Physically Educated/Literate Person? Journal of Teaching in Physical Education. 36, 3 -19

Haywood, K. and Getchell, N. (2009) Life span motor development, Champaign, IL: Human Kinetics.

Hopsicker, P. (2009) 'Polanyi's “From-To” Knowing and His Contribution to the Phenomenology of Skilled Motor Behavior', Journal of the Philosophy of Sport, vol. 36, pp. 76-87

Howard, J. and McInnes, K. (2010) 'Thinking Through the Challenge of a play-based curriculum, increasing playfulness via co-construction', in Moyles, J.R. (ed.) Thinking about play, Berkshire: Open University Press.

Howard, J. (2002) 'Eliciting young children's perceptions of play, work and learning using the activity apperception story procedure', Early Child Development and Care, 172(5), pp. 489-502.

Huneric, Altunsoz and Goodway (2016)

Jurbula, P. (2015) What is Physical Literacy, really? Quest, 67(4) pp 367-383.

Kirk, D. (2010) Physical Education Futures, London: Routledge.

Laevers, F., Moons, J., Daems, M., Debruyckere, G., Declercq, B., Silkens, K. and Snoeck, G. (2005) Sics [Ziko] Well-being and involvement in care-a process-oriented self-evaluation instrument for care settings.

Laevers, F. and Declercq, B. (2011) Raising levels of well-being and involvement in Milton Keynes Preschool Settings.

Laevers, F. (2000) 'Forward to Basics! Deep-Level-Learning and the Experiential Approach', Early years, 20(2), pp. 20-29.

Laevers, F. (1994) The Leuven Involvement Scale for Young Children. Oxford: Gecko publishing.

Logan, S., Robinson, L., Webster, E.K. and Barber, L. (2013) 'Exploring pre-schoolers' engagement and perceived physical competence in an autonomy-based object control skill 
Macdonald, D. (2003) 'Curriculum change and the post-modern world: Is the school curriculum-reform movement an anachronism?’ Journal of Curriculum Studies, 35(2), pp. 139-149.

Maude, P. (2010) 'Physical literacy and the young child', in Whitehead, M.E. (ed.), Physical literacy throughout the lifecourse, London: Routledge.

Maynard, T. (2007) 'Outdoor play and learning', Education 3-13: International Journal of Primary, Elementary and Early Years Education, 35(4), pp. 305-307.

Maynard, T. and Waters, J. (2007) 'Learning in the outdoor environment: a missed opportunity?’ Early Years, 27(3), pp. 255-265.

McInnes, K., J. Howard, J., Miles, G. and K. Crowley, K. (2009) 'Behavioural differences exhibited by children when practising a task under formal and playful conditions', Educational and Child Psychology, 26(2), pp. 31-9.

Merleau-Ponty, M. (1962) Phenomenology of perception: An introduction, London: Routledge.

Moyles, J. (2010) The excellence of play, New York: McGraw-Hill International.

Mygind, E. (2007) 'A comparison between children’s physical activity levels at school and learning in an outdoor environment', Journal of Adventure Education and Outdoor Learning, 7(2), pp. 161-176.

Newby, P. (2010) Research methods for education London: Pearson Education.

Reeve, J. Jang, H. Carrell, D. Barch, J. and Jeon, S. (2004) 'Enhancing students' engagement by increasing teachers’ autonomy support', Motivation and Emotion vol. 28, pp. 147-169.

Robinson, L.E. (2011) 'Effect of a mastery climate motor program on object control skills and perceived physical competence in pre-schoolers', Research Quarterly for Exercise and Sport, 82(2), pp. 355-359.

Robinson, L. E., Rudisill, M. E., and Goodway, J. D. (2009). Instructional climates in preschool

children who are at-risk. Part II: Perceived physical competence. Research Quarterly for Exercise and

Sport, 80(3), 543-551.

Ryan, R.M. and Deci, E.L. (2000) 'Self-determination theory and the facilitation of intrinsic motivation, social development, and well-being', American Psychologist, 55(1), pp. 68-78. 
Spradley, J. P. (1980) Participant Observation, Belmont, USA: Wadsworth.

Stodden, D., Goodway, J., Langendorfer, S., Roberton, M., Rudisill, M., Garcia, C., and Garcia, L. (2008) 'A Developmental Perspective on the Role of Motor Skill Competence in Physical Activity: An Emergent Relationship’, Quest, 60(2), pp. 290-306.

Stolz, S.A. (2013) 'Phenomenology and physical education', Educational Philosophy and Theory, 45(9), pp. 949-962.

Talbot, M. (2007) 'An independent voice for physical education: a precious asset', Physical Education Matters, 2(4), pp. 6-8.

Ulrich, D. A. (2000). The Test of Gross Motor Development ( $2^{\text {nd }}$ Ed.). Austin, TX: Pro-ed.

Valentini, N.C. and Rudisill, M.E. (2004b) 'Motivational climate, motor-skill development, and perceived competence: two studies of developmentally delayed kindergarten children', Journal of Teaching in Physical Education, 23(3), pp.216-234.

Waite, S. (2010) 'Losing our way? The downward path for outdoor learning for children aged 2-11 years', Journal of Adventure Education and Outdoor Learning, 10(2), pp. 111 126.

Whitehead, M.E. (1990) 'Meaningful Existence, Embodiment and Physical Education' Journal of Philosophy of Education, 24(1), pp. 3-14.

Whitehead, M.E. (2010) Physical literacy: Throughout the lifecourse, London: Routledge.

Whitehead, M.E. (2013) 'Definition of Physical Literacy and clarification of related Issues', ICSSPE Bulletin - Journal of Sport Science and Physical Education, vol. 65, pp. 28-33.

Whitehead, M.E. (2016) The definition of physical literacy http://www.physicalliteracy.org.uk/ [accessed 23/6/2017]. 
Table 1: Cues that children use to distinguish between play and work

\begin{tabular}{|c|c|c|c|}
\hline Play & & Work & \\
\hline Emotional cues & Environmental cues & Emotional cues & Environmental cues \\
\hline Voluntary & On the floor & Compulsory & At a table \\
\hline Under child's control & $\begin{array}{l}\text { Lacks adult } \\
\text { involvement }\end{array}$ & Under adult control & $\begin{array}{l}\text { Includes adult } \\
\text { involvement }\end{array}$ \\
\hline Easy & $\begin{array}{l}\text { No adult evaluation } \\
\text { Can be continued-focus } \\
\text { on the process }\end{array}$ & Hard & $\begin{array}{l}\text { Includes adult evaluation } \\
\text { Has to finish-focus on the } \\
\text { product }\end{array}$ \\
\hline Fun & Physical & Can be fun & Not physical \\
\hline
\end{tabular}


Table 2 Research Design

\begin{tabular}{|c|c|c|c|c|c|c|c|c|}
\hline \multicolumn{4}{|c|}{ PHASE ONE } & \multicolumn{4}{|c|}{ PHASE TWO } & \multirow{2}{*}{\begin{tabular}{|c} 
PHASE THREE \\
JAN \\
Yr 3
\end{tabular}} \\
\hline \multirow[t]{2}{*}{$\begin{array}{l}\text { FEB- } \\
\text { MAY } \\
\text { Yr1 } \\
\end{array}$} & $\begin{array}{l}\text { JUNE } \\
\text { Yr } 1\end{array}$ & $\begin{array}{r}\text { JULY } \\
\text { Yr } 1\end{array}$ & $\begin{array}{r}\text { NOV } \\
\text { Yr1 }\end{array}$ & $\begin{array}{l}\text { DEC } \\
\text { Yr } 1\end{array}$ & $\begin{array}{c}\text { FEB } \\
\text { Yr } 2 \\
\text { T1 } \\
\end{array}$ & $\begin{array}{c}\text { JULY } \\
\text { Yr2 } \\
\text { T2 } \\
\end{array}$ & $\begin{array}{c}\text { DEC } \\
\text { Yr2 } \\
\text { T3 } \\
\end{array}$ & \\
\hline & $\begin{array}{c}\text { Pilot } \\
\text { interview }\end{array}$ & \multirow{6}{*}{$\begin{array}{l}\text { Semi-structured } \\
\text { interviews }\end{array}$} & \multirow{6}{*}{$\begin{array}{c}\text { Respondent } \\
\text { validation }\end{array}$} & \multirow{6}{*}{$\begin{array}{c}\text { Pilot } \\
\text { instruments }\end{array}$} & \multirow[t]{2}{*}{ TGMD-2 } & \multirow[t]{2}{*}{ TGMD-2 } & \multirow[t]{2}{*}{ TGMD-2 } & \multirow{6}{*}{$\begin{array}{c}\text { Analysis of } \\
\text { schools' data, } \\
\text { with data from } \\
\text { phase two. }\end{array}$} \\
\hline \multirow{5}{*}{\multicolumn{2}{|c|}{$\begin{array}{c}\text { Documentary } \\
\text { analysis }\end{array}$}} & & & & & & & \\
\hline & & & & & Harter Scale & $\begin{array}{c}\text { Semi structured } \\
\text { interview } \\
\text { teachers school } \\
\text { A \& B } \\
\end{array}$ & Harter Scale & \\
\hline & & & & & \multicolumn{3}{|c|}{ Participant observation } & \\
\hline & & & & & \multicolumn{3}{|c|}{ Leuven involvement } & \\
\hline & & & & & \multicolumn{3}{|c|}{ Video } & \\
\hline
\end{tabular}


Table 3 scores for observations using the Leuven Involvement Scale.

\begin{tabular}{|l|l|l|l|l|l|l|l|}
\hline & Total & $\begin{array}{l}\text { Score 5 } \\
\text { Extremely } \\
\text { high }\end{array}$ & $\begin{array}{l}\text { Score 4 } \\
\text { High }\end{array}$ & $\begin{array}{l}\text { Score 3 } \\
\text { Moderate }\end{array}$ & $\begin{array}{l}\text { Score 2 } \\
\text { Low }\end{array}$ & $\begin{array}{l}\text { Score 1 } \\
\text { Extremely } \\
\text { low }\end{array}$ & Mean score \\
\hline $\begin{array}{l}\text { No. of } \\
\text { observations }\end{array}$ & 56 & 17 & 16 & 14 & 8 & 1 & 3.7 \\
\hline $\begin{array}{l}\% \text { of } \\
\text { observations }\end{array}$ & $100 \%$ & $30.4 \%$ & $28.6 \%$ & $25 \%$ & $14.3 \%$ & $1.8 \%$ & \\
\hline
\end{tabular}

Table 4 Percentage of observations in each category of the Leuven Involvement scale

\begin{tabular}{|l|c|c|c|}
\hline $\begin{array}{l}\text { Category of } \\
\text { involvement score }\end{array}$ & $\begin{array}{c}\text { High / very high } \\
\text { engagement } \\
4 \text { and } 5\end{array}$ & $\begin{array}{c}\text { Moderate } \\
\text { engagement }\end{array}$ & $\begin{array}{c}\text { Low / very low } \\
\text { engagement } \\
1 \text { and } 2\end{array}$ \\
\hline $\begin{array}{l}\text { Percentage of } \\
\text { observations }\end{array}$ & $59 \%$ & 3 & $16 \%$ \\
\hline
\end{tabular}

Table 5: Involvement scores and percentage per category

\begin{tabular}{|l|l|l|l|}
\hline \multirow{2}{*}{ Task } & \multicolumn{2}{|c|}{ Involvement } & \multirow{2}{*}{ Total } \\
\cline { 2 - 3 } & Very low/ low & Moderate involvement & High/very high \\
\end{tabular}




\begin{tabular}{|l|c|c|c|c|}
\hline & & & & \\
\hline Directed & $24.1 \%$ & $34.5 \%$ & $41.4 \%$ & $100.0 \%$ \\
\hline Choice & $7.4 \%$ & $14.8 \%$ & $77.8 \%$ & $100.0 \%$ \\
\hline
\end{tabular}

Response to reviewers

Thank you for the detailed reviews which have been extremely useful in helping to find a way of presenting this highly complex mixed methods study.

\section{Reviewer 1}

We have re written the paper with more focus on the mixed methods outlining the rationale for the research design. We have also altered the presentation of data to be representative of the mixed methods research design and presented more qualitative data to show the balance in the research design.

We have added in a section about analysis of mixed methods and a section about reliability and validity in this research paradigm.

The data for movement competence have been presented differently to ensure that there is no confusion about the claims of the study that would be beyond the scope of the research.

The lack of object control improvement is highlighted in this study as there remain opportunities for instruction in physical development within this curriculum and so should be improving with appropriate instruction as in Goodway's work on SKIP (Successful Kinaesthetic Instruction for Pre-schoolers). This shows that pupils of this age do make significant progress when appropriate instruction is given - Goodway, J.D. and Branta, C.F. (2003), hence the concluding comments in the paper about the need for professional development.

The perceived competence scale has been used extensively in studies with pupils of this age, and we have included references to support this as well as acknowledging the limitations that 
Reviewer 2

We have explained the choice of schools and explained that this was not in relation to urban /rural.

We have altered the focus of the paper in response to reviewer 1 and the editor's recommendations, as such the data regarding the schools is no longer presented and word count

would not allow us to expand on this issue in this paper.

Due changing the presentation of the study to mixed methods and not quantitative sections of the quantitative data have been removed for more of a balance of data from other methods, therefore the section with inter-rater reliability has been removed.

The comment about lily and the yoga stance was quoted directly from the field notes and was the wording the researcher used to describe the posture.

The focus of the study was not on psychomotor skills rather on the embodied nature of learning that is closely aligned to the underlying philosophy of physical literacy. 
